\title{
An assessment of the implementation of the National Therapeutic Programme for pregnant women within the City of Cape Town district
}

\author{
H Grundlingh, ${ }^{1}$ M Nutr; M Herselman, ${ }^{1} \mathrm{PhD} ; \mathrm{P}$ O Iversen,,${ }^{1,2} \mathrm{MD}$ \\ ${ }^{1}$ Division of Human Nutrition, Faculty of Medicine and Health Sciences, Stellenbosch University and Tygerberg Academic Hospital, Cape Town, \\ South Africa \\ ${ }^{2}$ Department of Nutrition, Institute of Basic Medical Sciences, University of Oslo, Oslo, Norway
}

Corresponding author: P O Iversen (p.o.iversen@medisin.uio.no)

Background. An integrated Nutritional Supplementation Programme (NSP), now termed the National Therapeutic Programme (NTP), was initiated in 1995 to address South Africa's pressing nutritional problems. It specifically focuses on maternal health, including iron deficiency anaemia and underweight among pregnant women, but its implementation and efficacy for pregnant women has not been evaluated. Objectives. To determine (i) whether pregnant women qualified for both the food and micronutrient (folate and iron) supplementation offered by the programme; (ii) whether those who qualified received such supplementation; and (iii) whether those who qualified were aware of the rationale for the supplementations.

Methods. A cross-sectional descriptive study was conducted in all primary healthcare antenatal clinics in the City of Cape Town district, involving 114 women. All were interviewed using a questionnaire, their mid-upper arm circumference was measured, and their symphysisfundus measurements (where documented) were obtained from their medical files.

Results. Only $5 \%$ of the women qualified for the food supplementation, while all qualified for the micronutrient supplementation. Only 1 of the 6 participants who qualified for food supplementation was registered and received it. Seventy (61\%) of the participants received the micronutrient supplementation and used it correctly. Twenty-nine (25\%) participants had heard about the food supplementations for pregnant women and $54(47 \%)$ had heard about the micronutrient supplementations.

Conclusion. The food supplementation was not successfully implemented among pregnant women. The strategy requires further attention within the antenatal clinics.

S Afr Med J 2013;103(8):549-551. DOI:10.7196/SAMJ.6670

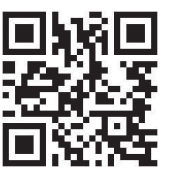

Maternal nutritional health during pregnancy plays an important role in influencing fetal development and birth, as well as the risks for short- and long-term adverse health outcomes for the infant. ${ }^{[1-4]}$ Pregnant women with a poor nutritional intake benefit from nutrient supplementation. ${ }^{[5]}$

In 1995 the Department of Health implemented a national nutrition policy called the National Supplementation Programme (NSP), and now termed the National Therapeutic Programme (NTP). The aim of the NTP was to reduce the incidence firstly, of low birthweight infants and secondly, of iron deficiency anaemia in pregnant women. ${ }^{[6]}$ Three nationwide surveys conducted in 1999, 2005 and 2008 showed that food security is a major problem in South Africa (SA), in particular among disadvantaged groups. ${ }^{[7]}$

No study has fully evaluated the implementation of the NTP and its efficacy and benefit to pregnant women. The present study evaluated the NTP by determining (i) if pregnant women qualified for the NTP food and micronutrient (folate and iron) supplementations; (ii) whether the women actually received the supplementations; and (iii) women's awareness of importance and roles of the supplementations.

\section{Methods \\ Study population}

The study population consisted of all pregnant women $\geq 18$ years visiting free, public, primary health centres (PHCs) in the City of Cape Town district that hosted antenatal clinics. All other health facilities providing antenatal care were excluded.
The majority of the clinics were situated in the low sociodemographic areas of the City of Cape Town district, (Gugulethu, Khayelitsha, Masiphumelele in Noordhoek, Manenberg and Du Noon) known for their informal settlements, poor sanitation and high crime rates. ${ }^{[8]}$

At the time of data collection (2 May 2008 - 30 June 2008) 14 PHCs hosted an antenatal clinic. Given the organisation and catchment areas of these clinics, it was not feasible to randomise participants for inclusion. Hence non-random sampling was used to select $7-10$ pregnant women at each clinic, giving a total sample size of 114 .

\section{Data collection}

Participants had a choice of language between Afrikaans, English or isiXhosa.

Participants' ages, weeks of gestation and symphysis-fundus measurements were obtained from their medical files. Insufficient growth was defined as a symphysis-fundus measurement below the 10th percentile or a measurement that showed growth stagnation/decline, ${ }^{[9]}$ and dictated inclusion in the NTP. The midupper arm circumference (MUAC) was determined in triplicate, using a measuring tape, to determine eligibility for the NTP food supplementation. ${ }^{[10]}$ A mean MUAC below $23 \mathrm{~cm}$ was used as an entry criterion. ${ }^{[11]}$

A structured sub-sectioned questionnaire was used to obtain sociodemographic data and details of food and micronutrient supplementation. Questions were framed to determine the extent of the participants' understanding of the importance of the food/micronutrient supplementation(s) during pregnancy, 
as well as whether participants in the NTP indeed received the supplementation(s).

The study was approved by the ethics committees of Stellenbosch University and the Department of Health.

\section{Results \\ Characteristics of the total study population}

Among the 114 participants, the largest population group was black patients (63\%, median age 25.7 years), followed by coloured patients (35\%, median age 27.1 years). Less than $2 \%$ were white (median age 25.0 years) and there were no Indian women.

Forty-two percent of participants were married, 37\% lived alone and $18 \%$ lived with their partner; $3 \%$ were divorced and none were widows. More blacks participants (46\%), compared with coloured ones (23\%), lived alone. Among the coloured participants 50\% were married compared to $38 \%$ among the blacks; $14 \%$ of the black women and $23 \%$ of coloured ones lived with a partner.

Ten percent of the participants had completed primary school, $40 \%$ had grade 8 - 10, and $41 \%$ had grade 11 - 12 education or higher; the remaining $9 \%$ had received no formal education.

Regarding employment status, $55 \%$ of the women were 'stay-athome' mothers/partners or unemployed, $34 \%$ were regular wageearners and $8 \%$ were self-employed. Although being a student was not classified as 'work', $3 \%$ gave it as an 'other' option.

Table 1 shows the monthly income, and money spent on food, per household. There were large differences. While 5\% had no income for the household, $13 \%$ had an income of more than R5 000 per month. Expenditure on food per month also varied: $13 \%$ spent $<$ R100 whereas $15 \%$ spent more than R401. While $39 \%$ of black women spent R101 - R200 of their monthly income on food, $55 \%$ of coloured women spent R201 - R400.

Reasons for clinic attendance on the day of observations Reasons given by the 114 pregnant women for attending the clinic on the observation day were: acute or chronic disease (2\%), first visit related to pregnancy (34\%), follow-up visit related to pregnancy (57\%), and other (7\%). Fourteen percent were HIV infected, but none had AIDS.

\section{Breastfeeding}

Ninety of the 114 pregnant women planned to breastfeed. Among the 24 who did not plan to breastfeed, half gave HIV infection as the

\begin{tabular}{|c|c|}
\hline Rand per month & Participants $(N=114), \%$ \\
\hline \multicolumn{2}{|l|}{ Monthly income } \\
\hline 0 & 5 \\
\hline $1-500$ & 9 \\
\hline $501-1000$ & 15 \\
\hline $1001-3000$ & 42 \\
\hline $3001-5000$ & 16 \\
\hline$>5001$ & 13 \\
\hline \multicolumn{2}{|c|}{ Monthly food expenses } \\
\hline $0-100$ & 13 \\
\hline $101-200$ & 33 \\
\hline $201-400$ & 39 \\
\hline$>401$ & 15 \\
\hline
\end{tabular}

reason; the remainder cited a wide variety of reasons that included work responsibilities, belief that baby milk formulas/products would be better, inability to breastfeed or anticipation of pain if they did, concern that it would spoil their figures and the belief that their husbands would not allow it. Some still had to decide whether they were going to breastfeed.

\section{Participants who qualified for and received the various supplementation programmes}

The average gestational week was 24 for the 114 participants on the day of the clinic visit; $44 \%$ had not yet reached 20 weeks of gestation and in $11 \%$ the pregnancy was $<12$ weeks. For those for whom the day of investigation was their first visit to the clinic, $23 \%$ were at $<12$ weeks gestation, $49 \%$ were between 12 and 20 weeks and, $28 \%$ were at $>20$ weeks.

The main findings with regard to qualification for, and receipt of, food supplementation are depicted in Table 2. Forty-four percent of the participants had a symphysis-fundus measurement above the entry level for inclusion to the NTP, while $56 \%$ did not. Among those who did, the average MUAC was $29.6 \mathrm{~cm}$ for the total study population, whereas $68 \%$ had MUAC between 24.7 and $34.4 \mathrm{~cm}$. The average MUAC values for black and coloured participants were $30.2 \mathrm{~cm}$ and $28.6 \mathrm{~cm}$, respectively. Six (5\%) participants had a MUAC $<23 \mathrm{~cm}$, thus qualifying for the NTP, but only one actually received the food supplementation. She admitted to sharing the products with her children at home. The other 5 did not receive the food nutritional supplementation (which was brought to the attention of the clinic-nurse).

All participants were eligible to receive the micronutrient supplementation, of whom $61 \%$ had received it, typically during the 16th week of gestation. A small number experienced side effects $(26 \%)$ or problems in taking the supplementation (9\%).

\section{Awareness regarding the supplementations}

Of the 70 participants who received the micronutrient supplementation, 40 knew why they had to take it, citing its role in building/ protecting/helping the baby (65\%), ensuring the development of the baby (5\%), and improving low maternal iron levels (20\%), as well as iron's role in the development of the baby's spine (3\%). A further $3 \%$ each believed that the supplement improved the appetite, allayed dizziness and benefited the pregnancy in general.

Forty-six percent of participants recalled that staff had informed them about micronutrient supplementation. Whereas the majority (81\%) found the verbal information helpful, $6 \%$ found it confusing and $13 \%$ said they had not found it helpful at all. Only $4 \%$ of the participants indicated that they had received written information about micronutrient supplementation during pregnancy, all finding this helpful. After being shown the packages of the supplements, 70 indicated that they recognised them.

Table 2. Participants and the supplementation programmes

\begin{tabular}{lll}
\hline Supplementation programme & $\begin{array}{l}\text { Food } \\
\boldsymbol{n}(\%)\end{array}$ & $\begin{array}{l}\text { Micronutrients } \\
\boldsymbol{n}(\%)\end{array}$ \\
\hline Awareness & $29(25)$ & $53(47)$ \\
$\quad$ Heard about it & $27(24)$ & $61(70)$ \\
Seen it & $6(5)$ & $114(100)$ \\
Qualify for supplementation & 1 of $6(17)$ & 70 of $75(93)^{*}$ \\
Received supplementation & \\
$\begin{array}{l}\text { *39 participants attending the clinic for the first visit time had not yet received the } \\
\text { micronutrient supplementation. }\end{array}$
\end{tabular}




\section{Opinions of participants who did not receive supplementation}

The 44 (39\%) participants who did not receive any nutritional supplementation (food supplementation and/or micronutrients) were asked if they understood why they had not received it. Eighteen percent had no particular opinion, 70\% thought it was because it was their first visit to the clinic, 5\% stated that it was related to their HIV positivity, $5 \%$ thought it was because they had seen a private doctor, and one woman had had a blood test which, she believed, indicated that she did not require supplements.

\section{Discussion}

The main aim of this study was to evaluate the implementation of the NTP for pregnant women of disadvantaged groups. While only a minority of the participants knew about the NTP, awareness of the availability of micronutrients was fairly good.

Nearly $80 \%$ of the participants who visited the clinic for the first time were past 12 weeks of pregnancy. This is disappointing in the context of the prevention of neural tube defects, since the rostral end of the neural tube typically closes within the first month of pregnancy. This late antenatal clinic attendance may be explained by poor sexual information and guidance, which causes women to fail to realise that they are pregnant. Alternatively, women may be afraid to inform their employers about the pregnancy for fear of losing their jobs.

That only 6 of the pregnant women qualified for the food nutritional supplements is positive in terms of the prevalence of underweight among pregnant women in the study area - previous research found that $9 \%$ of the mothers with children under five years were underweight. ${ }^{[12]}$ It is of concern, however, that only 1 of these 6 women was registered in the NTP. This begs the question: Do nursing personnel know the entry criteria for registration of pregnant women to the NTP? Moreover, roughly half of the participants did not have a symphysis-fundus measurement. This could partly be explained by the fact that this was their first visit to the clinic, but might also reflect understaffing and inappropriate resources. ${ }^{[13]}$

When participants were asked if they had ever heard of the NTP micronutrient supplementation, only 53 participants could answer positively, this number rising to 70 when participants were shown the drug packages. Among the 70 participants who took the micronutrient supplementations, about $40 \%$ had no idea why they should take them, perhaps reflecting poor information from the professional nurse or disinterest on the part of the recipient. (It is doubtful that complaints regarding side effects would have contributed to suboptimal compliance).

Limitations to the study include the low number of participants attending the clinics, possibly due to the fact that, during data collection, xenophobic attacks were prominent in the investigation areas. Also, our study did not include investigation of awareness, insight and experience regarding the NTP on the part of nursing personnel. Furthermore, the study captured women attending antenatal facilities in PHCs in the City of Cape Town district, situated in the relatively more affluent Western Cape Province.

\section{Conclusion}

Only a quarter of pregnant women surveyed had heard about the NTP food supplementation, though half knew about the micronutrient supplementation. Although only 6 of the pregnant women qualified for the NTP food supplements, it is concerning that 5 of these 6 participants were never registered on the NTP.

To improve the health of pregnant women requiring nutritional support through the NTP, there is a need to ensure adequacy of resources for the programme by reducing the workload, and increasing the training, of healthcare workers, and improving the provision of information about the programme to pregnant women.

Acknowledgements. We thank all the participants and the staff at the clinics for their contributions to this study.

\section{References}

1. Victora CG, Adair L, Fall C, et al. Maternal and child undernutrition: Consequences for adult health an human capital. Lancet 2008;371(9609):340-357. [http://dx.doi/org/10.1016/S0140-6736(07)61692-4]

Ehrenberg HM, Dierker L, Milluzzi C, Mercer BM. Low maternal weight, failure to thrive in pregnancy. and adverse pregnancy outcomes. Am J Obstet Gynecol 2003;189(6):1726-1730.

3. Geary CA, Fonseca RA, Caskey MA, Malloy MH. Improved growth and decreased morbidities in $<1000$ g nenates after early managent changes. J Perinat 2008:28(5):347-353. [http//dx.doi/ . [http://dx.doi/ (1)

riksen C. Ellingvag A, et al. First year growth among very low birth weight infants. Acta Paediatr 2010 Apr;99(4):556-562. [http://dx.doi/org/.1111/j.1651-2227.2009.01667.x]

5. Bhutta ZA, Ahmed T, Black RE, et al. What works? Interventions for maternal and child undernutrition and survival. Lancet 2008;371(9610):417-440. [http://dx.doi/org/10.1016/S0140-6736(07)61693-6]

6. Labadarios D, Steyn NP, Mgijima C, Daldla N. Review of the South African nutrition policy 1994 2002 and targets for 2007: Achievements and challenges. Nutrition 2005;21(1):100-108. [http://dx.doi/ org/10.1016/j.nut.2004.09.014]

7. Labadarios D, McHiza ZJ, Steyn NP, et al. Food security in South Africa: A review of national surveys. Bull World Health Organ 2011;89(12):891-899. [http://dx.doi/org/10.2471/BLT.11.089243]

. Millennium Development Goals Country Report 2010. http://www.statssa.gov.za/news_archive/Docs/ MDGR_2010.pdf (accessed 4 January 2013).

Millennium Development Goals. http://www.who.int/topics/millennium_development goals/about/ en/index.html (accessed 4 January 2013).

10. WHO Expert Committee. Physical Status: The Use and Interpretation of Anthopometry. Geneva: World Health Organization, 1995.

11. Western Cape Department of Health. Policy and Implementation Guidelines for the Nutrition Supplementation Programme of the Health Facility Based Nutrition Programme (HFBNP). Cape Supplementation Programme of the Health Facility
Town: Western Cape Provincial Government, 2007.

12. Iversen PO, Hoisaether EA, Morseth M, Herselman M. Diverging opinions of supplementation programmes between mothers of small children and staff at primary health clinics in the Western Cape Province of South Africa. Public Health Nutr 2011;14(5):923-930. [http://dx.doi/org/10.1017 S1368980010003319]

13. Iversen PO, Marais D, du Plessis L, Herselman M. Assessing nutrition intervention programmes that addressed malnutrition among young children in South Africa between 1994-2010. AFJAND 2012;12(2):5928-5945.

Accepted 24 January 2013. 